\title{
Novel Zn(II) Coordination Polymers Based on the Natural Molecue Bisdemethoxycurcumin
}

\author{
Laura Rodríguez-Cid, E. Carolina Sañudo, Ana M. Lópz-Periago, Arátzazu Gonzábz-Campo,
} Núra Aliaga-Alcalde, * and ConcepcióĐomingo*

\begin{abstract}
This article introduces a new family of coordination polymers (CPs) that contains a renewable curcumin derivative, the bisdemethoxycurcumin (BDMC), coordinated to $\mathrm{Zn}$ (II) centers. The reaction between $\mathrm{BDMC}$ and zinc acetate, performed under mild conditions in ethanol, provides a new 1D phase termed BDMCZn-1. In addition, dimensionality and porosity of this network have been expanded by studying the reaction occurring between three species, the BDMC, the $\mathrm{Zn}(\mathrm{II})$, and a ditopic colinker: 1,2-bis(4-pyridyl)ethylene, 1,3-bis(4-pyridyl)propane, or 4,4'-bipyridine. In total, seven new CPs are presented, named BDMCZn- $x$. The structures of five of them were elucidated by single-crystal X-ray diffraction. Moreover, we show that the combination of the latest technique with solid-state ${ }^{13} \mathrm{C}$ nuclear magnetic resonance is a powerful tool set to analyze the coordination modes of the BDMC, providing insight into the two unresolved structures. In the achievement of the new $\mathrm{CPs}$, we further discuss the coordination capacity of BDMC, the relevance of solvents, and supramolecular interactions.
\end{abstract}

\section{INTRODUCTION}

According to IUPAC, ${ }^{1}$ the chemistry of metal-organic frameworks (MOFs) and coordination polymers (CPs) is in the sixth position of the current list of top emerging technologies, which motivates a large amount of research on this topic. As any newly developed chemistry technology, sustainability criteria must be taken into account from the first stages in the design, regarding both molecular constituent elements and synthetic procedure. ${ }^{2}$ The main ingredients of CPs are the inorganic part, represented by metal ions or clusters, and the organic backbone containing neutral or charged linkers that form different structures in several dimensions. The search for cost-effective and sustainable sources for linkers has led to the study of bio-based natural molecules (vs fossil derived materials) to guarantee element renewability and the attainment of green chemistry. Examples of employed biolinkers for CPs building are peptides, oligopeptides, carbohydrates, amino acids, nucleobases, and porphyrins. $^{3-9}$ In the studied natural linkers, frequent drawbacks are the lack of symmetry factors in the molecule and the presence of considerable flexibility, which make the crystallization of CPs with high dimensionality challenging. In a more extended picture, a pro-active approach to sustainability would involve the consistent addition of new polytopic natural and biorenewable linkers in the creation of 1D-3D polymeric architectures for all kinds of purposes related to energy, gas adsorption, and catalysis. ${ }^{10}$ Additionally, the use of biocompat- ible molecules would option medical purposes, for example, as drug delivery systems or in diagnosis by imaging. ${ }^{11,12}$

Connected with the above, curcuminoids (CCMoids, Figure 1a) are diarylheptanoid bioderived molecules extracted from the renewable rhizomes of the plant Curcuma longa, ${ }^{13}$ although they can also be synthesized using the synthetic methods described by Pabon and others. ${ }^{14-16}$ These species, and particularly curcumin (CCM), the prevalent CCMoid in the turmeric rhizome, have been used since ancient times in food and medicine and as a natural dye. ${ }^{17-19}$ From a structural point of view, natural CCMoids have three potential sites toward metal-ligand coordination, consisting of one $\beta$ diketone/enol group and two phenolic rings with different substituents (Figure 1a). ${ }^{20}$ As polytopic linkers, CCMoids are perfect candidates for the synthesis of CPs, since they retain specific symmetry in the molecule, and possess moderate flexibility. These molecules can exhibit numerous coordination modes with metal ions, giving place to a high structural diversity in the crystallized products. There are many examples of the coordination of CCM and $3 d / 4 f / 5 d$ metal centers. ${ }^{21}$

Received: June 1, 2020

Revised: September 10, 2020

Published: September 11,2020 
(a)

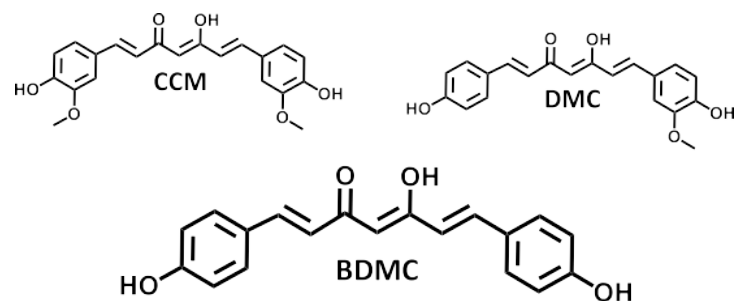

(b)

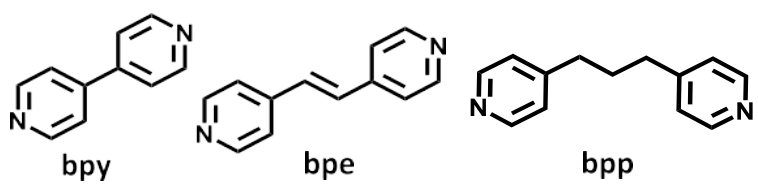

Figure 1. Molecular structures of (a) main CCMoids (CCM = curcumin, $\mathrm{DMC}=$ demethoxycurcumin, $\mathrm{BDMC}=$ bisdemethoxycurcumin) present in the turmeric root (central image), and (b) dipyridine colinkers used (bpy $=4,4^{\prime}$-bipyridine, bpe $=1,2$-bis $(4-$ pyridyl)ethylene, $\mathrm{bpp}=1,3$-bis(4-pyridyl)propane).

However, reported reactions regarding the coordination of metals with the rest of CCMoids from the turmeric root, i.e., bisdemethoxycurcumin (BDMC) and demethoxycurcumin (DMC) (Figure 1a), are less common. ${ }^{22-25}$ MOFs and CPs based on $\mathrm{CCM}^{26,27}$ have been proposed for drug delivery applications.

Besides the CCM CPs described in the literature by $\mathrm{Su}$ et al. ${ }^{26}$ and us, ${ }^{27}$ to the best of our knowledge, there are only a few more reported involving transition metals $(\mathrm{Co}$ (II) and $\mathrm{Ni}(\mathrm{II})$ ), also by some of us. ${ }^{28}$ In this respect, this work presents the first examples of a series ofCPs synthesized with a

$\mathrm{Zn}(\mathrm{II})$ source and the natural CCMoid BDMC. The significant symmetry and conjugated nature of this polytopic renewable biomolecule confer attractive characteristics for CPs synthesis, and to the best of our knowledge, this path remains unexplored. The reaction of BDMC with $\mathrm{Zn}$ (II) investigated in this work, performed in $\mathrm{EtOH}$, a green solvent, under solvothermal conditions, resulted in a dense 1D CP (BDMCZn-1). In addition, as a way to increase the dimensionality and porosity of the network, the use of ancillary linkers, chosen from the family of the dipyridines (1,2-bis(4pyridyl)ethylene (bpe), 1,3-bis(4-pyridyl)propane (bpp), and 4,4'-bipyridine (bpy)) in Figure 1b), was studied. ${ }^{29,30}$ With this procedure, seven new CPs, with $1 \mathrm{D}$ and $3 \mathrm{D}$ dimensionalities, were crystallized (BDMCZn1, 2a, 2b, 3, 4a, 4b, and $4 \mathrm{c})$. The structures of five of the newly synthesized compounds could be elucidated by single-crystal X-ray diffraction. Solid-state ${ }^{13} \mathrm{C}$ nuclear magnetic resonance (NMR) measurements were performed as a complementary technique to ascertain the different coordination modes of the BDMC molecule within the compounds. This technique is sensitive to small changes in the disposition, environment, and conformation of the analyzed molecules. ${ }^{31}$ The spectral data obtained from the unresolved crystalline materials were correlated to potential crystal topology and composition to outline the structures. This work shows a rich variety of crystallographic structures using a CCMoid aside from CCM, and solid-state ${ }^{13} \mathrm{C} \mathrm{NMR}$ as a handy characterization tool to discern coordination of such species. Our results aim to show renewable natural CCMoids as powerful polytopic building units toward the creation of future extended structures in CPs, providing useful characterization tools toward their analysis in the solid state.

\section{MATERIALS AND METHODS}

Materials. $\mathrm{Zn}(\mathrm{OAc})_{2} \cdot 2 \mathrm{H}_{2} \mathrm{O}$ and the ancillary linkers (bpy, bpe, and bpe) were provided by Sigma-Aldrich. BDMC was synthesized using a modification of Pabon method. ${ }^{14}$ EtOH was supplied by Scharlab.

Synthetic Method. Synthesized CPs were obtained using a solvothermal methodology and $\mathrm{EtOH}$ as a solvent. Reactions were carried out in $10 \mathrm{~mL}$ Pyrex vials with hermetic closures, which were placed in an oven at $80{ }^{\circ} \mathrm{C}$ for 3 days. The end products were collected after cooling down the vials to room temperature. Crystals, placed on the walls and at the bottom of the vials, were recovered directly from the mother solution and washed with fresh solvent before drying.

BDMCZn-1. $30.00 \mathrm{mg}(0.097 \mathrm{mmol})$ of BDMC and $21.36 \mathrm{mg}$ $(0.097 \mathrm{mmol})$ of $\mathrm{Zn}(\mathrm{OAc})_{2} \cdot 2 \mathrm{H}_{2} \mathrm{O}$ were mixed in $2 \mathrm{~mL}$ of EtOH. The vial was stirred ultrasonically up to the complete solubilization of all reagents to proceed with the solvothermal treatment. Yield 56-60 wt $\%$. ATR-FTIR data $\left(\mathrm{cm}^{-1}\right)$ : 1603 ( $\left.\mathrm{vC} \mathrm{C}_{\text {aromatic }}\right), 1591$ (C

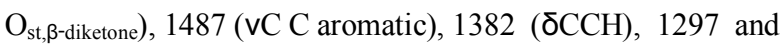
1234 (C-Ost phenolic $_{\text {) }}, 1157$ (opp $\mathrm{CCH}_{\text {aromatic }}$ and $\left.\mathrm{CCH}_{\text {skeletal }}\right), 970$ ( $\mathrm{CH}_{\delta}$ opp). EA (wt \%) data for [Zn(BDMC) $\left.(\mathrm{EtOH})\right]$ or $\mathrm{ZnC}_{21} \mathrm{H}_{19} \mathrm{O}_{5}$ $\left(416.74 \mathrm{~g} \cdot \mathrm{mol}^{-1}\right)$ calculated C: $60.37, \mathrm{H}: 4.89$; found C: $60.30, \mathrm{H}$ : 5.16 .

BDMCZn-2a and $2 b$. Both were synthesized as 1 but with an extra reagent added consisting of either $8.86 \mathrm{mg}(0.048 \mathrm{mmol})$ or $17.73 \mathrm{mg}$ $(0.097 \mathrm{mmol})$ of bpe. Yields 52-70 wt \%. ATR-FTIR data of BDMCZn-2a ( $\left.\mathrm{cm}^{-1}\right)$ : 1603 ( $\left(\mathrm{VC} \mathrm{C}_{\text {aromatic }}\right), 1537$ (C O $\left.\mathrm{O}_{\text {st } \beta \text {-diketone }}\right)$, 1494 (vC $\left.\mathrm{C}_{\text {aromatic }}\right), 1407,1240$ (C-Ost phenolic $_{\text {) }}$ ) 1158 (opp $\mathrm{CCH}_{\text {aromatic }}$ and $\left.\mathrm{CCH}_{\text {skeletal }}\right), 968$ ( $\mathrm{CH}_{\delta}$ opp). $\mathrm{EA}$ (wt \%) for $[\mathrm{Zn}(\mathrm{BDMC})(\mathrm{bpe})(\mathrm{OAc})]_{n} \cdot 2 \mathrm{nH}_{2} \mathrm{O}$ or $\mathrm{ZnC}_{33} \mathrm{H}_{28} \mathrm{O}_{6} \mathrm{~N}_{2} \cdot 2 \mathrm{H}_{2} \mathrm{O}(649.47$ $\mathrm{g} \cdot \mathrm{mol}^{-1}$ ) calculated $\mathrm{C}: 60.98, \mathrm{H}: 4.96, \mathrm{~N}: 4.31$. found $\mathrm{C}: 61.05, \mathrm{H}$ : 4.76, N: 4.54.

ATR-FTIR data of BDMCZn-2b $\left(\mathrm{cm}^{-1}\right)$ : 1602 ( $\mathrm{vC} \mathrm{C}$ aromatic),

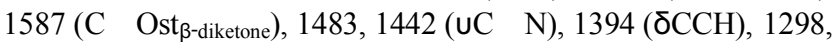
1243 (C-Ost phenolic $_{\text {) }}, 1154$ (opp $\mathrm{CCH}_{\text {aromatic }}$ and $\left.\mathrm{CCH}_{\text {skeletal }}\right), 981$ ( $\mathrm{CH}_{\delta}$ opp$)$. EA, the best fit of the found data (C: 64.41, H: 4.42, N: $2.91 \mathrm{wt} \%$ ) was obtained by using a molar ratio for Zn:BDMC:bpe of 1:1:0.5 (C: 64.88, H: 4.14, N: $3.03 \mathrm{wt} \%$ ), therefore resulting in the formulas [Zn(BDMC)(bpe $)_{0.5}$ ] or $\mathrm{ZnC}_{25} \mathrm{H}_{19} \mathrm{O}_{4} \mathrm{~N}\left(462.79 \mathrm{~g} \cdot \mathrm{mol}^{-1}\right)$.

$B D M C Z n-3$. The system was synthesized as -1 but adding either $19.29 \mathrm{mg}(0.048 \mathrm{mmol})$ or $38.58 \mathrm{mg}(0.097 \mathrm{mmol})$ of bpp. Yield $75-$ $80 \mathrm{wt} \%$. ATR-FTIR data $\left(\mathrm{cm}^{-1}\right): 1599$ ( $\left.\mathrm{vC} \mathrm{C}_{\text {aromatic }}\right), 1590$ (C

Ost $\beta$-diketone), 1482 ( $\left.\mathrm{VC} \mathrm{C}_{\text {aromatic }}\right), 1439$ (UC N), 1384 (ठCCH), 1262 (C-Ost phenolic $), 1157$ (oppCCH $_{\text {aromatic }}$ and $\left.\mathrm{CCH}_{\text {skeletal }}\right), 968$ ( $\mathrm{CH}_{\delta}$ opp). EA (wt \%) for [Zn(BDMC)(bpp) $\left.)_{1 / 2}\right]_{n} \cdot n / 2 \mathrm{EtOH}$ or $\mathrm{Zn}_{2} \mathrm{C}_{51} \mathrm{H}_{42} \mathrm{O}_{8} \mathrm{~N}_{2} \cdot \mathrm{C}_{2} \mathrm{H}_{6} \mathrm{O}\left(987.68 \mathrm{~g} \cdot \mathrm{mol}^{-1}\right)$ calculated C: $64.45, \mathrm{H}$ : 4.9, N: 2.84, found C: 64.03, H: 5.21, N: 2.91.

BDMCZn-4a, $4 b$, and $4 c$. The three systems were synthesized as BDMCZn-1 but adding either $15.19 \mathrm{mg}(0.048 \mathrm{mmol})$ or $30.38 \mathrm{mg}$ $(0.097 \mathrm{mmol})$ of bpy. BDMCZn-4c was the only compound obtained in significant quantity, with a yield of 38-54 wt \%. ATR-FTIR data $\left(\mathrm{cm}^{-1}\right)$ : 1614 ( $\left.\mathrm{vC} \mathrm{C}_{\text {ring }}\right), 1590$ (C O st s-diketone $_{\text {) }}$ 1483(vC $\left.\mathrm{C}_{\text {aromatic }}\right), 1382(\mathrm{\delta CCH}), 1261\left(\mathrm{C}-\mathrm{Ost}_{\text {phenolic }}\right), 1155$ (opp $\mathrm{CCH}_{\text {aromatic }}$ and $\left.\mathrm{CCH}_{\text {skeletal }}\right), 965$ ( $\mathrm{CH}_{\delta}$ opp). EA, the best fit of the data found (C: $58.71, \mathrm{H}: 4.07, \mathrm{~N}: 3.4 \mathrm{wt} \%$ ) was obtained by using a molar ratio for $\mathrm{Zn}: \mathrm{BDMC}$ :bpy of 1:1:0.5 (C: 59.33, H: 4,56, N: $2.88 \mathrm{wt} \%$ ) with $2 \mathrm{H}_{2} \mathrm{O}$ molecules in the structure, therefore resulting in the formulas $\left[\mathrm{Zn}(\mathrm{BDMC})(\text { bpy })_{0.5}\right]_{n} \cdot 2 n \mathrm{H}_{2} \mathrm{O}$ or $\mathrm{ZnC}_{24} \mathrm{H}_{18} \mathrm{O}_{4} \mathrm{~N} \cdot 2 \mathrm{H}_{2} \mathrm{O}$ (485.8 g. mol).

Characterization. Prepared samples were characterized first by routine powder X-ray diffraction (PXRD) by recording the patterns on a Siemens D-5000 diffractometer with $\mathrm{Cu}$ Ka radiation. Singlecrystal X-ray diffraction (SCXRD) data for BDMCZn-1 were 
collected on a Bruker APEXII Qazar CCD diffractometer equipped (Grup de Magnetisme i Molecules Funcionals,
Universitat de Barcelona) at Mo Ka wavelength using $\phi$ and $\omega$ scans at $100 \mathrm{~K}$. 
The structures were solved by intrinsic phasing methods $(\text { SHELXT) })^{32}$ and refined on $\mathrm{F}^{2}$ (SHELXL). Hydrogen atoms were included on calculated positions, riding on their carrier atoms. Data for the rest of the characterized species (BDMCZn-2a,-3,-4a,-4b) were collected at the XALOC beamline ${ }^{33}$ at ALBA synchrotron (Spain) K with a 0.72931 A wavelength using the Dectris Pilatus $6 \mathrm{M}$ detector at $100 \mathrm{~K}$. The $\phi$ scan was repeated at three different $K$ angles $\left(0^{\circ}, 45^{\circ}\right.$, and $\left.90^{\circ}\right)$ and merged afterward to increase the completeness and redundancy when possible. Data were indexed, integrated, and scaled using the XDS software. ${ }^{34}$ Crystallographic data for all compounds are summarized in Table S1 in the SI, and the corresponding CIF files have been deposited in the Cambridge Crystallographic Data Centre and can be accessed free of charge at https://www.ccdc.cam.ac.uk/structures/(CCDC depositionnumbers 1991279-1991283).

Sample chemical compositions $(\mathrm{C}, \mathrm{H}$, and $\mathrm{N})$ were assessed by elemental analysis (EA, Thermo Carlo Erba Flash 2000). Thermogravimetric analysis (TGA, NETZSCH-STA 449 F1 Jupiter), performed up to $600{ }^{\circ} \mathrm{C}$ in air or Ar, was used to determine the thermal stability and composition of some samples. Attenuated total reflectance-Fourier transform infrared (ATR-FTIR) spectra were obtained in a FTIR JASCO 4700LE equipment using the ATR accessory with a resolution of $4 \mathrm{~cm}^{-1}$ and 32 scans. For the measurements, ca. $5 \mathrm{mg}$ of the powdered samples were deposited covering the crystal of the ATR accessory and pressed with the pressure tip. The solid-state ${ }^{13} \mathrm{C}$ NMR experiments were performed on a Bruker Avance III at a magnetic field of 9.4 T, equipped with a double channel $4.0 \mathrm{~mm}$ MAS probe. Sample spinning was set to 10 $\mathrm{kHz}$. A contact time of $2500 \mu \mathrm{s}(63 \mathrm{kHz})$, a recycle delay of $1 \mathrm{~s}, 27 \mathrm{k}$ scans (overall experimental time $8 \mathrm{~h}$ ), and a decoupling power of 83.3 $\mathrm{kHz}$ were used in all experiments. Pure adamantane was used as external chemical shift reference ( $\mathrm{CH}$ signal at $29.5 \mathrm{ppm}$ ).

\section{RESULTS AND DISCUSSION}

The combination of solvothermal conditions and $\mathrm{EtOH}$ provides seven new CPs with BDMC as the principal linker and $\mathrm{Zn}(\mathrm{II})$ as the metallic node. BDMCZn-1 could be resolved by SCXRD using a conventional radiation source. Nevertheless, BDMCZn-2a, -3, -4a, and -4b compounds precipitated as spherulitic crystals, in which each crystal was composed from small subunits of only a few microns. Consequently, for the SCXRD analysis, a synchrotron source was necessary. Unfortunately, the obtained crystals for BDMCZn-2b and $4 c$ did not present enough quality for analysis, together with TGA, ATR-FTIR, and EA data, were then used to provide further insight in their structures regarding main formulas, coordination mode, and dimensionality.

Crystal Structures. BDMCZn-1, with stoichiometry $[\mathrm{Zn}(\mathrm{BDMC})(\mathrm{EtOH})]_{n}$, crystallizes in the monoclinic $P 2_{1} / c$ space group. Crystallographic parameters for this structure are detailed in Table S1. In the asymmetric unit, one $\mathrm{Zn}$ (II) atom appears tetracoordinated, having the basal plane occupied by the $\beta$-diketone of one BDMC linker and one $\mathrm{EtOH}$ molecule; meanwhile, in the apical position the metallic center coordinates to the phenolic ring of a neighboring BDMC linker (Figure 2a). The pseudotetrahedral geometry of the $\mathrm{Zn}(\mathrm{II})$ is imposed by the coordination with the two oxygen atoms in the $\beta$-diketone (angles $\mathrm{O}-\mathrm{Zn}-\mathrm{O}$ between $99^{\circ}$ and $120^{\circ}$ ). Each BDMC is coordinated to two different $\mathrm{Zn}$ (II) atoms by the $\beta$-diketone and one phenolic ring, while the second phenol remains protonated. As a consequence, the system presents a $1 \mathrm{D}$ zigzag chain where successive BDMC molecules form angles of $85.50^{\circ}$ (Figure $2 \mathrm{~b}$ ). The chains are held together in a 3D structure by hydrogen bonds established

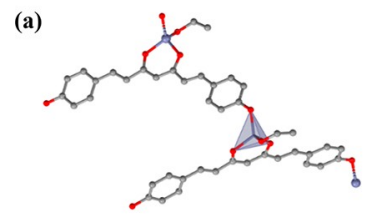

(b)
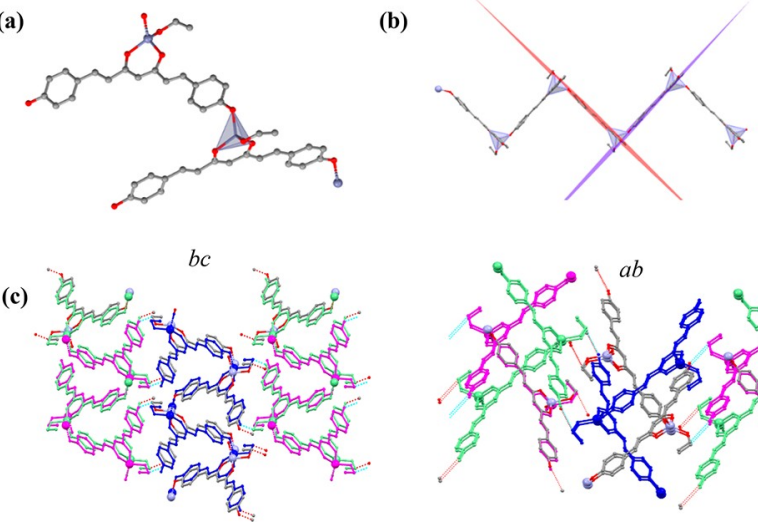

Figure 2. Schematic representation of the crystal structure of compound BDMCZn-1: (a) repeating unit showing the coordination mode of $\mathrm{Zn}(\mathrm{II})$ and BDMC, (b) zigzag chain in the 1D structure, and (c) extended 3D framework through $\mathrm{H}$-bonding projected in the $a$ and $c$ directions. Color code: $\mathrm{C}$, gray; $\mathrm{O}$, red; and $\mathrm{Zn}$, blue.

through the coordinated ethanol molecules (Figure 2c). The result is a compact packing with negligible structural porosity. The PXRD pattern obtained for BDMCZn-1 indicates high purity for the precipitated powder (Figure $\mathrm{S} 1$ ).

BDMCZn-2a presents a $[\mathrm{Zn}(\mathrm{BDMC})(\mathrm{bpe})(\mathrm{OAc})]_{n} \cdot 2 \mathrm{nH}_{2} \mathrm{O}$ stoichiometry. This compound crystallizes in the monoclinic $P 2{ }_{1} / c$ space group (Table S1), as well as BDMCZn-1, but its structure involves bpe molecules as colinkers. The asymmetric unit contains a single pentacoordinate $\mathrm{Zn}$ (II) atom bonded to the $\beta$-diketone of one BDMC, two pyridine $\mathrm{N}$ atoms of two additional bpe colinkers, and one oxygen from the acetate ligand. The $\mathrm{Zn}(\mathrm{II})$ ion adopts a square-based pyramidal geometry with the $\beta$-diketone, the acetate, and one of the bpe colinkers on the basal plane and the second bpe at the apical position (Figure 3a). Overall, the geometry is slightly distorted $(\mathrm{T}=0.43)$, with angles smaller than $90^{\circ}$ in the bonds that implicate the oxygen atoms of the $\beta$-diketone (between $85.4^{\circ}$ and $88.1^{\circ}$ ) and larger in the angle between the two N-donor linkers $\left(94.88^{\circ}\right)$. A similar coordination number has been observed in the past in CPs and MOFs, as well as when $\mathrm{Zn}(\mathrm{II})$

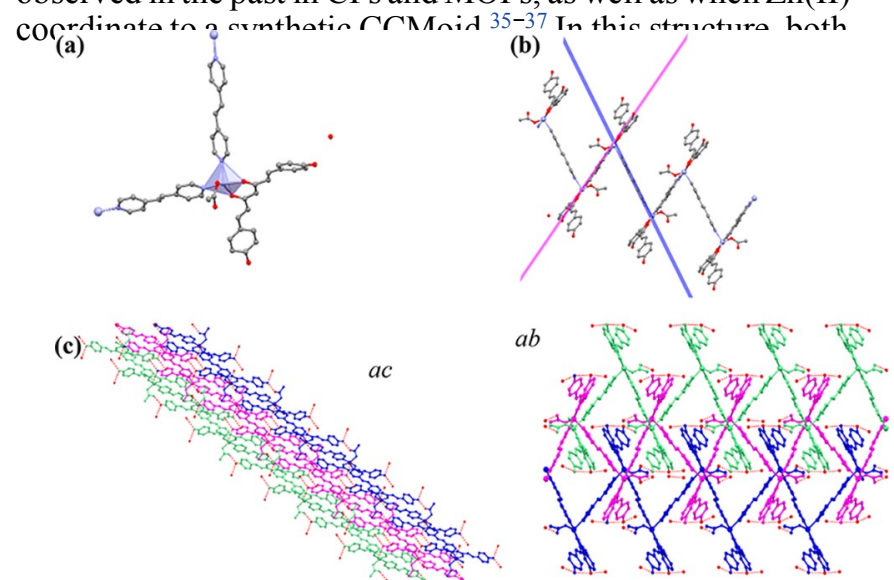


phenol groups of the BDMC molecule remain protonated and do not participate in the coordination to the metal, which is exclusively established through the $\beta$-diketone. Therefore, a new 1D zigzag array is formed by coordinative bonds established exclusively between the $\mathrm{Zn}$ (II) metal centers and the ditopic bpe molecules (with an angle of $64.58^{\circ}$, Figure $3 \mathrm{~b}$ ). In the supramolecular structure, the chains are held together by hydrogen bonds established between the remaining protonated phenol groups in the BDMC molecules and the acetate groups of different chains, with half of those through water bridges (Figure 3c). Again, the result is a dense structure with a negligible porosity (calculated using Mercury). Although the general disposition of $\mathrm{Zn}(\mathrm{BDMC})(\mathrm{OAc})$ units attached through the bpe is similar to other CCMoid-CPs published with $\mathrm{Co}$ (II) and $\mathrm{Ni}$ (II) using bpy, ${ }^{28}$ the molecular blocks of BDMCZn-2a are unique in the sense that each $\mathrm{Zn}$ unit coordinates to BDMC and acetate ligands instead of coordinating only to CCMoid molecules. The comparison between the PXRD of BDMCZn-2a and the pattern calculated from the single crystal structure indicates contamination with a different phase (see peaks at $2 \theta=5.96^{\circ}$ and $8.62^{\circ}$ ) (Figure $\mathrm{S} 1)$. This fact could be related to the low stability of the crystals in the absence of solvent (Figure S2), which produces changes in the structure during the PXRD measurement. Actually, the mixture $\mathrm{Zn}$ :BDMC:bpe has a complex crystallization behavior, since the reduction of the molar ratio of bpe (from 1 to 0.5 with respect to $\mathrm{Zn}(\mathrm{II})$ ) provides the new compound BDMCZn-2b, with a different PXRD pattern (Figure S1) ofBDMCZn-2a. Unfortunately, further characterization of the new compound was hampered by the poor quality of the crystals found. Its composition was estimated using EA data and corroborated by solid-state ${ }^{13} \mathrm{C}$ NMR and ATR-FTIR.

BDMCZn-3. This system presents a $\left[\mathrm{Zn}(\mathrm{BDMC})(\mathrm{bpp})_{0.5}\right]_{n}$. $n / 2 \mathrm{EtOH}$ stoichiometry and crystallizes in the orthorhombic $P 2{ }_{1}$ space group (Table S1). The repeating unit has a similar composition as BDMCZn-1, but now EtOH groups are replaced with bpp colinkers. As a result, 3D architecture is found in contrast to the $1 \mathrm{D}$ observed for BDMCZn-1. The structure of BDMCZn-3 is highly complex, with four crystallographically different $\mathrm{Zn}$ (II) atoms, all of them tetracoordinated (Figure 4a), and four independent BDMC units. Each pseudotetrahedral $\mathrm{Zn}$ (II) is bonded on the basal plane to the $\beta$-diketone of one BDMC linker and to one phenolic ring of a neighbor. The apical position is occupied by the pyridinic moiety of a bpp colinker. Hence, as described in BDMCZn-1, each BDMC is coordinated to two different $\mathrm{Zn}(\mathrm{II})$ atoms, through the $\beta$-diketone and one phenol ring, while the second phenol group remains protonated. The basic unit is constituted by zigzag [ $\mathrm{Zn}(\mathrm{BDMC})]_{n}$ chains extended in two perpendicular directions with an angle of $86.81^{\circ}$ (Figure $4 b$ ). These units are attached by the colinker bpp (Figure 4c) that adopts an L-shaped conformation, reducing in a great manner its length. The dense packing of this basic construction leads to interpenetration of the elements within the 3D structure (Figure 4d), giving place to a dense material with null porosity (calculated by Mercury).

BDMCZn-4a, $-4 b$, and $-4 c$. The three compounds display similar stability and precipitate simultaneously from the reagent mixture. Nevertheless, single crystals of BDMCZn-4a and BDMCZn-4b could be resolved by isolating them by hand from the bulk constituted mainly by the unresolved powdered BDMCZn-4c phase. Both compounds (BDMCZn-4a and (a)

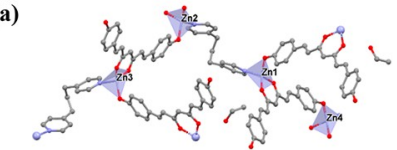

(c)

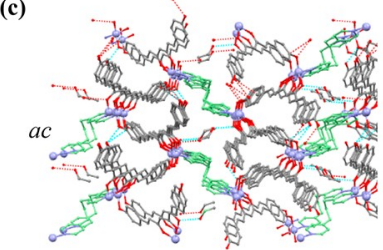

(d)

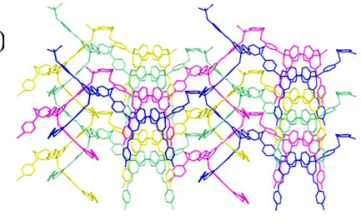

(b)

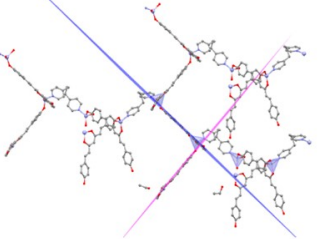

Figure 4. Schematic representation of the crystal structure of compound BDMCZn-3: (a) repeating unit showing the coordination mode of $\mathrm{Zn}$ (II) and BDMC, (b) projections of the zigzag basic unit chain, (c) projection of the 3D structures in the $b$ and $a$ directions, and (d) views of the interpenetrated structure, without and with the

space filling function in Mercury. Color code: $\mathrm{C}$, gray; $\mathrm{O}$, red; $\mathrm{N}$, blue; and $\mathrm{Zn}$, light blue.

BDMCZn-4b) are rather similar and have alike stoichiometry, with formulae $\left[\mathrm{Zn}_{2}(\mathrm{BDMC})_{2}(\mathrm{bpy})\right]_{n} \cdot n \mathrm{H}_{2} \mathrm{O} \cdot n \mathrm{EtOH}$ and $\left[\mathrm{Zn}_{2}(\mathrm{BDMC})_{2}(\mathrm{bpy})\right]_{n} \cdot 2 n \mathrm{EtOH}$, respectively, differentiating themselves in the nature and number of adsorbed solvent molecules. Even though these two systems present similarities, they crystallize in different space groups, $C 2 / c$ and $P 2{ }_{1} / n$ (Table S1), for BDMCZn-4a and BDMCZn-4b, in that order.

Both structures are formed by dinuclear units connected through the ligands. Each dimer displays a $\mathrm{Zn}_{2} \mathrm{O}_{6}$ core formed by two pentacoordinate crystallographically equivalent $\mathrm{Zn}(\mathrm{II})$

atoms (Figure $5 \mathrm{a}, \mathrm{b})^{37-39}$ coordinated each to a $\beta$-diketone moiety from one BDMC unit and one pyridinic group, from

the $4,4^{\prime}$-bpy, in addition to two phenolate groups from

neighboring CCMoid molecules that act as the bridging ligands within the dimeric cluster. Therefore, the coordination sphere of the metallic centers in BDMCZn-4a and BDMCZn$4 \mathrm{~b}$ is the same; however, the geometry of the $\mathrm{Zn}$ (II) ions differ

between structures. In BDMCZn-4a, each $\mathrm{Zn}(\mathrm{II})$ center adopts a square based pyramidal geometry $(\mathrm{T}=0.28)$ with four oxygen atoms from three different BDMC linkers on the basal plane (depicted in Figure $5 \mathrm{a}$, in which $\beta$-diketone is shown in red and phenolate in black) and one $\mathrm{N}$ atom from a pyridine moiety in the apical position (Figure 5 a displayed in green). In BDMCZn-4a, the angles $\mathrm{O}-\mathrm{Zn}-\mathrm{N}$ are between $96.1^{\circ}$ and $108.2^{\circ}$ and the angles $\mathrm{O}-\mathrm{Zn}-\mathrm{O}$ are in the range 76.8-93. $4^{\circ}$. In contrast, the $\mathrm{Zn}(\mathrm{II})$ centers in BDMCZn-4b display a bipyramidal trigonal geometry $(\mathrm{T}=0.79)$ having at the apical positions a phenolate group (Figure $5 \mathrm{~b}$, in black) from a CCMoids and a half-coordinated $\beta$-diketone moiety from another (Figure $5 \mathrm{~b}$, in red). The equatorial positions contain similar fragments and include a pyridinic moiety (Figure 5b, in green). In BDMCZn-4b, the angles are smaller

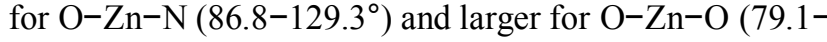


98.1 ${ }^{\circ}$ ). Again, BDMCZn-4a and BDMCZn-4b present 
4a: $\left[\mathrm{Zn}_{2}(\mathrm{BDMC})_{2}(\mathrm{bpy})\right]_{\mathrm{n}} \cdot \mathrm{nH}_{2} \mathrm{O} \cdot \mathrm{nEtOH} \quad \mathbf{4 b}:\left[\mathrm{Zn}_{2}(\mathrm{BDMC})_{2}(\mathrm{bpy})\right]_{\mathrm{n}} \cdot 2 \mathrm{EtOH}$
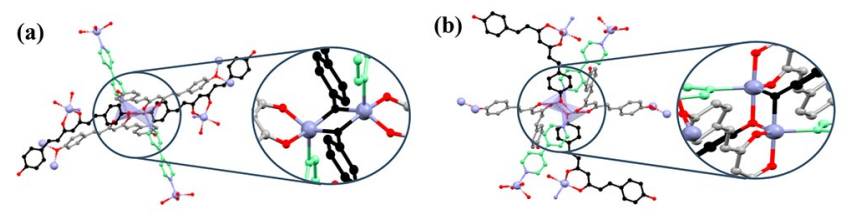

(c)
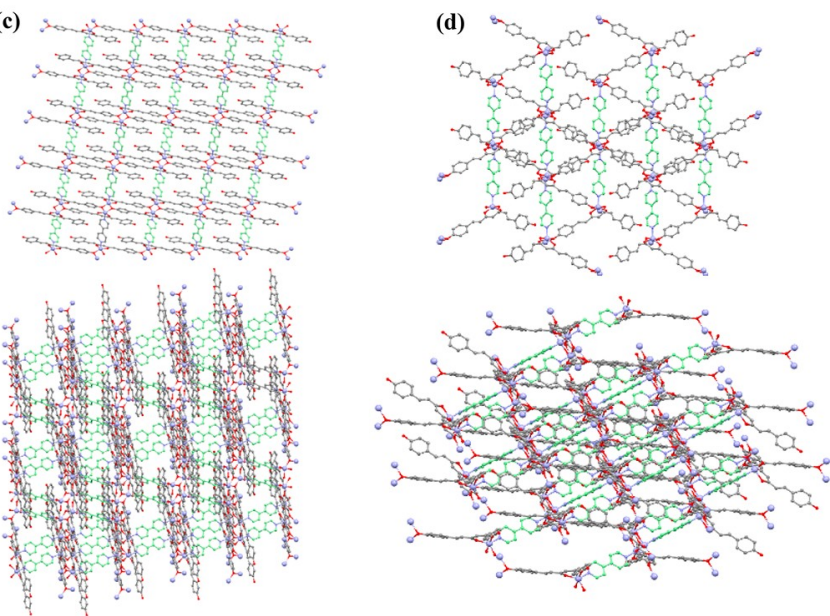

Figure 5. Schematic representation of the crystal structure of compounds BDMCZn-4a and BDMCZn-4b: $(a, b)$ repeating units showing the coordination modes of $\mathrm{Zn}$ (II) and BDMC, and (c,d) two different projections of the $3 \mathrm{D}$ structures. Color code: $\mathrm{C}$, gray; $\mathrm{O}$, red; and $\mathrm{Zn}$, light blue; bipyridine molecules in green and BDMC forming bridges in black.

generally similar trends in the way of expanding and connecting the dimers through the phenolate bridges and the bpy. Both structures display all the BDMC units coordinated through the $\beta$-diketone moiety to one $\mathrm{Zn}(\mathrm{II})$ ion and one phenolate ring to another center, remaining protonated the second phenolate in the CCMoid unit and giving an overall 3D structure (Figure 5c,d).

Another important difference between these two products resides in the incorporated solvents, $\mathrm{H}_{2} \mathrm{O}$ and $\mathrm{EtOH}$ in BDMCZn-4a, and exclusively EtOH in BDMCZn-4b, whose intermolecular interactions add disparity between the two 3D structures (Figure 6a,b). The void space in BDMCZn-4a take up $20.2 \mathrm{vol} \%$ of the unit cell volume. The porosity is organized in $1 \mathrm{D}$ channels extended in the $b$ axis. The EtOH/ $\mathrm{H}_{2} \mathrm{O}$ molecules fill up such porous and are distributed in pairs, relating through an inversion center, having strong hydrogen bonds between one EtOH and one $\mathrm{H}_{2} \mathrm{O}$ molecule within the sets (with a $\mathrm{O}_{\mathrm{H} 2 \mathrm{O}} \cdots \mathrm{H}-\mathrm{OEtOH}$ distance of $2.630 \AA$ and angle of $\left.164.9^{\circ}\right)$. In addition, each one of these molecules presents several interactions with the surroundings, displaying $\mathrm{O}_{\beta \text {-diketone }}-\mathrm{O}_{\mathrm{H} 2 \mathrm{O}}, \mathrm{C}-\mathrm{H}_{\mathrm{py}} \cdots \mathrm{O}_{\mathrm{H} 2 \mathrm{O}}$, and $\mathrm{C}-\mathrm{H}_{\mathrm{CCMoid}} \cdots \mathrm{O}_{\mathrm{EtOH}}$ distances of 2.793, 2.874, and $3.636 \AA$ (showing in the last an angle of $169.64^{\circ}$ ). This crowded supramolecular network allows the interrelation of separated BDMC linkers through the solvent molecules (Figure S3). For BDMCZn-4b, the structural porosity is reduced to $12.6 \mathrm{vol} \%$, constituted by isolated nonconnected pores where the $\mathrm{EtOH}$ molecules are placed. The adsorbed EtOH units are disordered, displaying, in the solved structure, the same probability for two opposite positions at the same location. Now, the EtOH is confined in a smaller void, surrounded by pyridinic and CCMoid segments, with not as effective hydrogen bonding as in the former,
D

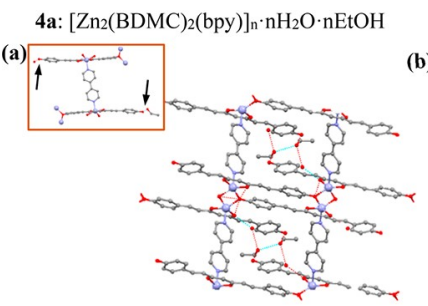

4b: $\left[\mathrm{Zn}_{2}(\mathrm{BDMC})_{2}(\mathrm{bpy})\right]_{\mathrm{n}} \cdot 2 \mathrm{EtOH}$

(b)

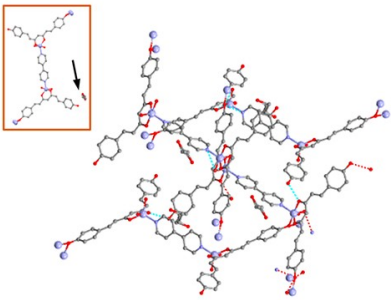

(c)
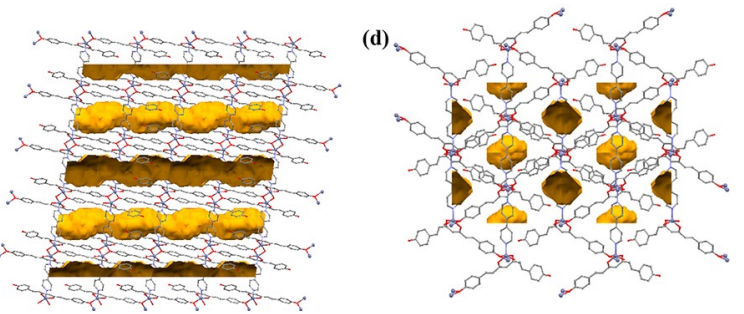
Figure 6. Schematic representation of the crystal and pore structures of compounds BDMCZn-4a and BDMCZn-4b: $(a, b)$ established Hbonding (arrows indicate the solvent molecules), and (c,d) void maps generated by Mercury showing 1D channels in BDMCZn-4a and isolated pores in BDMCZn-4b. Color code: $\mathrm{C}$, gray; $\mathrm{O}$, red; $\mathrm{N}$, blue; and $\mathrm{Zn}$, light blue.

presenting short Ophenol $^{\cdots} \cdot \mathrm{H}-\mathrm{O}_{\text {EtOH }}$ distances $(2.941 \AA)$ but small angles; such poor interactions allow the dual disposition of the molecule in the crystal (Figure 6c,d).

In the case of BDMCZn-4c, its structure could not be resolved even though it was the major phase obtained in the solvothermal treatment of $\mathrm{Zn}: \mathrm{BDMC}$ :bpy mixtures. For this compound, knowledge of the composition and formulas was acquired using EA and TGA (SI) data together with solid-state ${ }^{13} \mathrm{C}$ NMR studies and ATR-FTIR spectrum.

Solid-State ${ }^{13} \mathrm{C}$ NMR. BDMCZn-1, $-2 \mathrm{a},-2 \mathrm{~b},-3$, and $-4 \mathrm{c}$ crystalline phases were further analyzed by solid-state ${ }^{13} \mathrm{C}$ NMR. This technique has been successfully used in the characterization of CCM in the solid state, ${ }^{38-40}$ and it is of great assistance in the case of microcrystalline materials, such as MOFs and COFs ${ }^{41,42}$ Here, the analysis of the free BDMC linker, together with the correlation with the previously elucidated crystal structures by single crystal XRD, was used to provide insight on the unresolved structures (BDMCZn-2b and $4 \mathrm{c}$ phases). The solid-state ${ }^{13} \mathrm{C}$ NMR spectra of the mentioned species are shown in Figure 7. The assignment of the signals relates by comparison to previous reports on curcumin and solid-state ${ }^{13} \mathrm{C}$ NMR studies of the neat BDMC in solution. ${ }^{38}$

For pristine BDMC, the signal related to the methine carbon (at the center of the CCMoid skeleton, $\mathrm{C}_{1}$ in Figure 7) at $103.7 \mathrm{ppm}$, together with the two highly separated $\beta$-diketone shifts, $\mathrm{C}_{2}$ and $\mathrm{C}_{2}$, at 191.9 and $176.8 \mathrm{ppm}$, proves the stabilization of the keto-enol form vs the diketone. In addition, the signals of the $\mathrm{C}_{8}$ and $\mathrm{C}_{8}$ (connected to the hydroxyl groups) appear differentiated, at 160.8 and 157.3 ppm, probably due to effect of the keto-enol form and different surroundings for both endings of the molecule. The rest of the signals, from the diarylheptanoid skeleton and additional aromatic groups, fall in the 115-145 ppm region, where it is feasible to discriminate among them, split in their majority. Taking into account the literature and simulations, they follow a $\mathrm{C}_{7}\left(\mathrm{C}_{7^{\prime}}\right)-\mathrm{C}_{6}\left(\mathrm{C}_{6^{\prime}}\right)-\mathrm{C}_{3}\left(\mathrm{C}_{3^{\prime}}\right)-\mathrm{C}_{5}\left(\mathrm{C}_{5^{\prime}}\right)-\mathrm{C}_{4}\left(\mathrm{C}_{4^{\prime}}\right)$ 


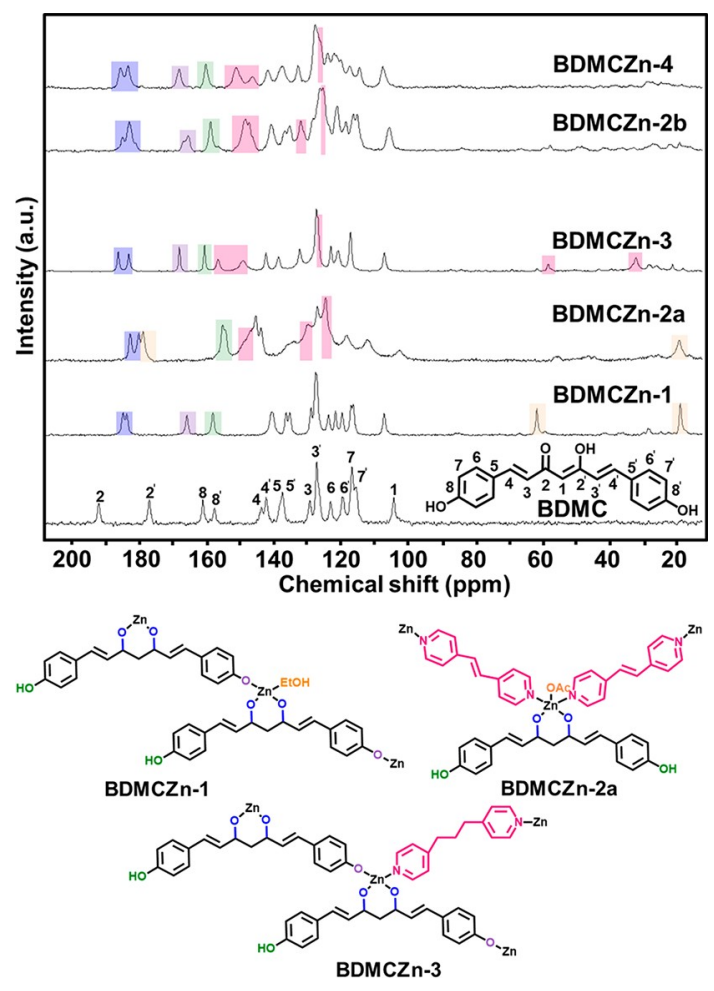

Figure 7. Solid-state ${ }^{13} \mathrm{C}$ NMR of pristine $\mathrm{BDMC}$ and compounds BDMCZn-1, BDMCZn-2a, BDMCZn-3, BDMCZn-2b, and BDMCZn-4c, showing also peak assignments.

order, from highest to lowest field, in the range mentioned above. $^{38}$

In BDMCZn-1 and BDMCZn-3, the chemical shifts of $\mathrm{C}_{2}$ and $\mathrm{C}_{2^{\prime}}$ appear closer now and at lower fields than pristine BDMC (184.6 and 183.5 ppm for BDMCZn- 1 and 186.1 and $182.9 \mathrm{ppm}$ for $\mathrm{BDMCZn}-3$, respectively). This alignment is a consequence of the coordination with $\mathrm{Zn}(\mathrm{II})$, having $\mathrm{C}_{2}$ and $\mathrm{C}_{2}$ similar displacements. For BDMCZn-2a, the same thing happens; thus the signals appear at 182.5 and $179.9 \mathrm{ppm}$, respectively, although here the spectrum displays an additional signal coming from the $\mathrm{C} \mathrm{O}$ group in the acetate ligand coordinated to the metallic center (at $178.6 \mathrm{ppm}$, Figure 7). In addition, the $\mathrm{C}_{8^{\prime}}$ chemical displacement for BDMCZn-1 and -3 remain similarly to the free BDMC, as this linker also remains free in these structures, while the analogous $\left(\mathrm{C}_{8}\right)$ in each system displays shifts to lower fields than BDMC, due to the coordination of this phenol group to a $\mathrm{Zn}$ (II) center. If the two phenol groups in the phenyl rings remain free, as it happens in BDMCZn-2a, the displacement values of $\mathrm{C}_{8}$ and $\mathrm{C}_{8^{\prime}}$ are very similar and closer to those of pristine BDMC.

Additional features, such as the chemical shifts of the coordinated EtOH (18.10 and 60.96 ppm) in BDMCZn-1, can also be discriminated, as well as the signals of the coordinated acetate moiety in BDMCZn-2a (178.6 and 18.4 ppm). In a similar manner, chemical shifts of the pyridinic colinkers for BDMCZn-2a and BDMCZn-3 appear in the range 120-160

ppm (aromatic groups of bpe and bpp together with the double bond from the bpe system) and 30-60 ppm in the case of the aliphatic groups of BDMCZn-3. Their assignment was possible by comparing with the solid-state ${ }^{13} \mathrm{CNMR}$ spectra of the free colinkers, measured in the same conditions as the CPs.

The knowledge acquired on solid-state ${ }^{13} \mathrm{C}$ NMR from the direct comparison of BDMCZn-1, $-2 \mathrm{a}$ and -3 , related to their respective crystallographic structures, was used toward the analysis of the spectra of the unresolved systems BDMCZn-2b and $-4 \mathrm{c}$. Unfortunately, the necessity of a substantial amount of sample (ca. $100 \mathrm{mg}$ ) limited the use of the technique toward the analysis of the minor phases, such as BDMCZn-4a and $-4 b$. However, for BDMCZn-4c, general trends from the colinkers observed in BDMCZn-2a and BDMCZn-3 (Table S2) were applicable for the case of the bpy bridges. In addition, the displacements in the solid-state ${ }^{13} \mathrm{C}$ NMR spectra of BDMCZn-2b and BDMCZn-4c are similar and point to the coordination of their respective BDMC linkers through the keto/enol moiety and one phenolic ring. In both cases, the displacements of $\mathrm{C}_{2}-\mathrm{C}_{2}{ }^{\prime}$ and $\mathrm{C}_{8}-\mathrm{C}_{8^{\prime}}$ were similar to those found for BDMCZn-1 and BDMCZn-3. Furthermore, both spectra suggest exclusive coordination of the $\mathrm{Zn}(\mathrm{II})$ centers with BDMC and bpe or bpy, excluding the possibility of extra coordinated ethanol or acetate molecules. With all of the above taken into account, and the additional characterization data for composition obtained from ATR-IR (Figure S5b) and EA, the formation, in BDMCZn-2b, of a more extended structure than that found for BDMCZn-2a is presumed, due to the double coordination of the BDMC linker and the displacements of the bpe together with the estimated stoichiometry found by EA ([Zn(BDMC)(bpe $\left.\left.)_{0.5}\right]\right)$. Similarly, for BDMCZn-4c, the derived formulas, [ $\left.\mathrm{Zn}(\mathrm{BDMC})(\mathrm{bpy})_{0.5}\right]_{n} \cdot 2 n \mathrm{H}_{2} \mathrm{O}$, agrees with the TGA analysis that provides similar BDMC weight percentages and shows the existence of solvent within the structure together with coordinated bpy. Hence, the solid-state ${ }^{13} \mathrm{C}$ NMR spectrum also suggests the formation of a structure similar to that found for BDMCZn-3 (Figure 7), which includes the possibility of a different coordination number for the $\mathrm{Zn}(\mathrm{II})$ units (e.g., tetra- instead of pentacoordinate) within the structure comparing with BDMCZn-4a and $-4 \mathrm{~b}$.

These results are in concordance with the observed in the ATR-FTIR spectra. In the spectra of the CPs, a reduction of the band related with the $\mathrm{VOH}\left(3493-2890 \mathrm{~cm}^{-1}\right)$ is observed in comparison with that of the free BDMC, due to the coordination of the $\beta$-diketone and one of the phenol groups (Figure S5a). This also agrees well with the absence of bands around $1560 \mathrm{~cm}^{-1}$ (Figure S5b) in the CPs, due to the $\delta \mathrm{COH}$ in the enol and the hydroxyl groups according with the work of Kolev et al ${ }^{43}$ Additionally, the peculiar coordination of BDMCZn-2a (which preserves the protonation of the two phenols and coordination of an acetate to the metal center) presents a broad band in the carboxylic region (around 1600 $\mathrm{cm}^{-1}$, Figure $\mathrm{S} 5 \mathrm{~b}$ ), related to the acetate, with some of CCMoid nature overlapping with the bands related to the $\delta \mathrm{COH}$ vibrational mode with a similar intensity as in the pristine CCMoid.

Comparative Analysis and General Trends. Due to the variety of coordination numbers, metal geometries and coordination modes of the ligand BDMC that can be observed in the structures of this work (Table 1) and with the novelty in its use as a linker taken into account, a more in-depth analysis of them has been carried out. As mentioned previously, BDMC has three positions for metals to coordinate through the $\mathrm{O}_{2}-$ $\mathrm{O}_{3}$ in the keto/enol group and through the oxygens $\mathrm{O}_{1}$ and $\mathrm{O}_{4}$ in the phenyl rings. However, full BDMC coordination has not been observed in this work (with or without the use of colinkers). Indeed, triple coordination has only been described for $\mathrm{CPs}$ based on the pair $\mathrm{Zn}(\mathrm{II}) / \mathrm{CCM}$ precipitated in alcoholic media using solvents with a rather basic nature, such as dimethylacetamide (DMA) or dimethylformamide 
Table 1. Metal Coordination, Metal Geometry, and Coordination Mode of the BDMC in the CPs

\begin{tabular}{|c|c|c|c|}
\hline CP & $\mathrm{Zn}(\mathrm{II})$ coordination & $\begin{array}{l}\mathrm{Zn}(\mathrm{II}) \text { adopted } \\
\text { geometry }\end{array}$ & $\begin{array}{l}\text { BDMC } \\
\text { coordination mode* }\end{array}$ \\
\hline BDMCZn-1 & Tetracoordinate & Pseudo-tetrahedral & A \\
\hline BDMCZn-2a & Pentacoordinate & $\begin{array}{l}\text { Square-based } \\
\text { pyramidal }\end{array}$ & B \\
\hline BDMCZn-3 & Tetracoordinate & Pseudo-tetrahedral & A \\
\hline BDMCZn-4a & Pentacoordinate & $\begin{array}{l}\text { Square-based } \\
\text { pyramidal }\end{array}$ & A \\
\hline BDMCZn-4b & Pentacoordinate & Bipyramide trigonal & A \\
\hline & & & \\
\hline
\end{tabular}

(DMF). ${ }^{44}$ Our first trials indicated that the pair $\mathrm{Zn}(\mathrm{II}) /$ BDMC was not crystallized in any of these basic solvents.

Remarkably, coordination reactions worked well by using exclusively $\mathrm{EtOH}$, and proof of that is the formation of BDMCZn-1. However, in EtOH the number of coordinated sites for the BDMC molecule never reached its maximum, displaying one binding position in BDMCZn-2a and two in BDMCZn-1, -3 , and the -4 series, independently of the use of additional colinkers in the reactions. As expected, in all cases, the most reactive group is the central keto/enol moiety which always appears coordinated.

The obtained structures can be categorized using two features: (i) the absence or use of a dipyridinic colinker (considering its length and flexibility), and (ii) the adsorbed/ coordinated solvent molecules. Both factors affect significantly the coordination and conformation adopted by the main linker, BDMC. The analysis of the results indicates that, as expected, the addition of a dipyridine based colinker increased the dimensionality of the system with respect to BDMCZn-1, going from 1D to 3D. Only for BDMCZn-2a a 1D network was obtained, which seems to be favored by the inclusion of the large bpe molecule (distance $\mathrm{N}_{1}-\mathrm{N}_{2}$ of $9.37 \AA$ ) with a limited degree of flexibility. This colinker confers to the $\mathrm{Zn}$ (II) metal centers the possibility ofbeing located faraway (distance $\mathrm{Zn}-\mathrm{Zn}$ of $13.49 \AA$ ), thus restricting potential interactions between BDMC molecules and $\mathrm{Zn}$ (II) atoms, hindering in this way the coordination of the ligand through more than one site. Certainly, in BDMCZn-2a, the BDMC did not act as a linker extending the network of the $\mathrm{CP}$, but rather it is essentially a ligand that completes the coordination of $\mathrm{Zn}$ (II) center. BDMCZn-3 and the BDMCZn-4 series, involving bpp (with an L-shape due to its flexible aliphatic skeleton) and bpy,
Figure 8. Superimposition of the BDMC moieties in the asymmetric units of the different precipitated compounds, compared to pristine BDMC conformations: (a) BDMC $\cdot \mathrm{H}_{2} \mathrm{O}$ (gray), BDMCZn-1 (blue), BDMCZn-2a (purple), BDMCZn-3 (orange), BDMCZn-4a (green), and (b) BDMC (gray), BDMCZn-4b (yellow).

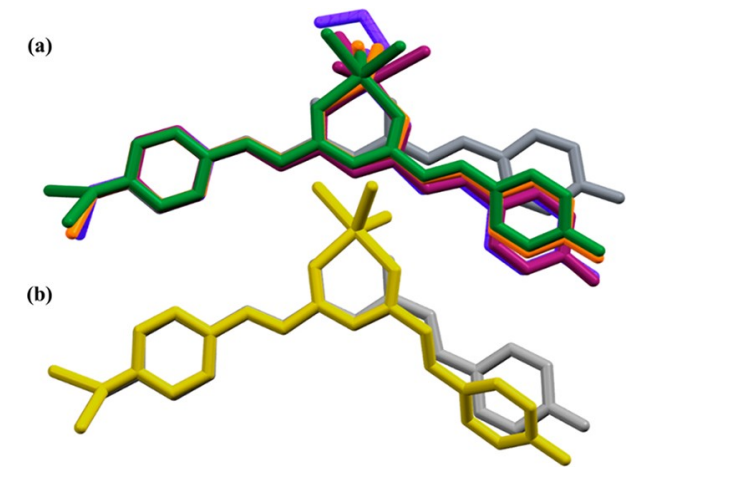

respectively, had shorter $\mathrm{N}_{1}-\mathrm{N}_{2}$ distances than BDMCZn-2a (6.87 and $7.06 \AA$, respectively). The length of these colinkers is short enough to allow the BDMC molecules to coordinate through two points (the keto/enol moiety and one phenolate group) to two neighboring $\mathrm{Zn}(\mathrm{II})$ atoms. These $\mathrm{CPs}$ are extended simultaneously by means of the BDMC and dipyridinic colinker, resulting in 3D structures with variable complexity.

For the analysis of the crystal structures based on the BDMC linker, the different disposition of the phenolic rings promoted by the conformations should be considered to have originated within the CCMoids skeleton (Figure 8). For that, it is 
worthwhile to pay attention to the networks described for the pristine and solvated BDMC ligand. ${ }^{45}$ Free BDMC prefers to crystallize together with solvent molecules to lower the crystal free energy, in which the solvent species fill voids and bind efficiently the host molecules providing an extended network with multipoint hydrogen bonding. Typically, adsorbed protic solvents are involved in the formation of the network by acting as bridges between consecutive BDMC units. Therefore,

BDMC molecules appear separate enough to adopt a nontensioned near-flat equilibrium conformation.

Previous works had shown that the asymmetric units of $\mathrm{BDMC} \cdot \mathrm{H}_{2} \mathrm{O}$ and $\mathrm{BDMC} \cdot \mathrm{MeOH}$ are composed of one molecule of BDMC with $\mathrm{O}_{1}-\mathrm{O}_{4}$ distances of 17.79 and $17.73 \AA$, respectively. ${ }^{46,47}$ On the contrary, nonsolvated BDMC structures develop a compact packing in which the molecules present strong and direct interactions among them. To achieve this, the BDMC adopts highly distorted conformations presenting curvy forms or segmented molecular backbones not fully extended, presenting in both cases shorter $\mathrm{O}_{1}-\mathrm{O}_{4}$ phenolate

between 16.41 and $17.06 \AA .^{46}$

distances

Similarly, the different BDMC conformations found in our CPs can be classified by analyzing the established short interactions and hydrogen bonding created with the solvent or even additional molecules. These interactions affect the overall BDMC architecture, with one side of the molecule remaining planar (typically the one containing the phenolic ring coordinated to the metal), with this being fully extended and defining here the reference plane $\mathrm{P} 1$ (which includes $\mathrm{C}_{3}$ to $\mathrm{C}_{8}$, Figure 7). The other side of the CCMoid molecule defines the plane $\mathrm{P} 2$ (from $\mathrm{C}_{3^{\prime}}$ to $\mathrm{C}_{8^{\prime}}$, Figure 7), which displays a high degree of possible conformations based on nonextended versions of the CCMoid skeleton adopted to promote improvements in the packing. Significant atomic distances between $\mathrm{O}_{1}-\mathrm{O}_{4}$ for the coordinated BDMC linkers and P1- P2 angles are shown in Table 2 for each resolved CP.

In BDMCZn-1, the CCMoid linker has a quasi-flat conformation with a $\mathrm{P} 1-\mathrm{P} 2$ angle of $10.32^{\circ}$ and one of the $\mathrm{O}_{1}-\mathrm{O}_{4}$ highest lengths $(17.32 \AA)$. Here, the BDMC molecules interact through the coordinated $\mathrm{EtOH}$ molecule. The context for BDMCZn-2a is quite different, since the BDMC coordinates the $\mathrm{Zn}$ (II) center through the keto/enol moiety and the network is exclusively extended by the bpe colinker. Hence, the colinkerestablishes the 3D structure, allowing extra structural degrees of freedom for the BDMC ligand. Therefore, 
Table 2. BDMC distances $\mathrm{O}_{1}-\mathrm{O}_{4}$ and angles $\mathrm{P} 1-\mathrm{P} 2$ in the different compounds. The schematic draw shows the linker conformation in each compound. Color code: $\mathrm{C}$ grey, $\mathrm{O}$ red $\mathrm{N}$ blue and $\mathrm{Zn}$ light blue

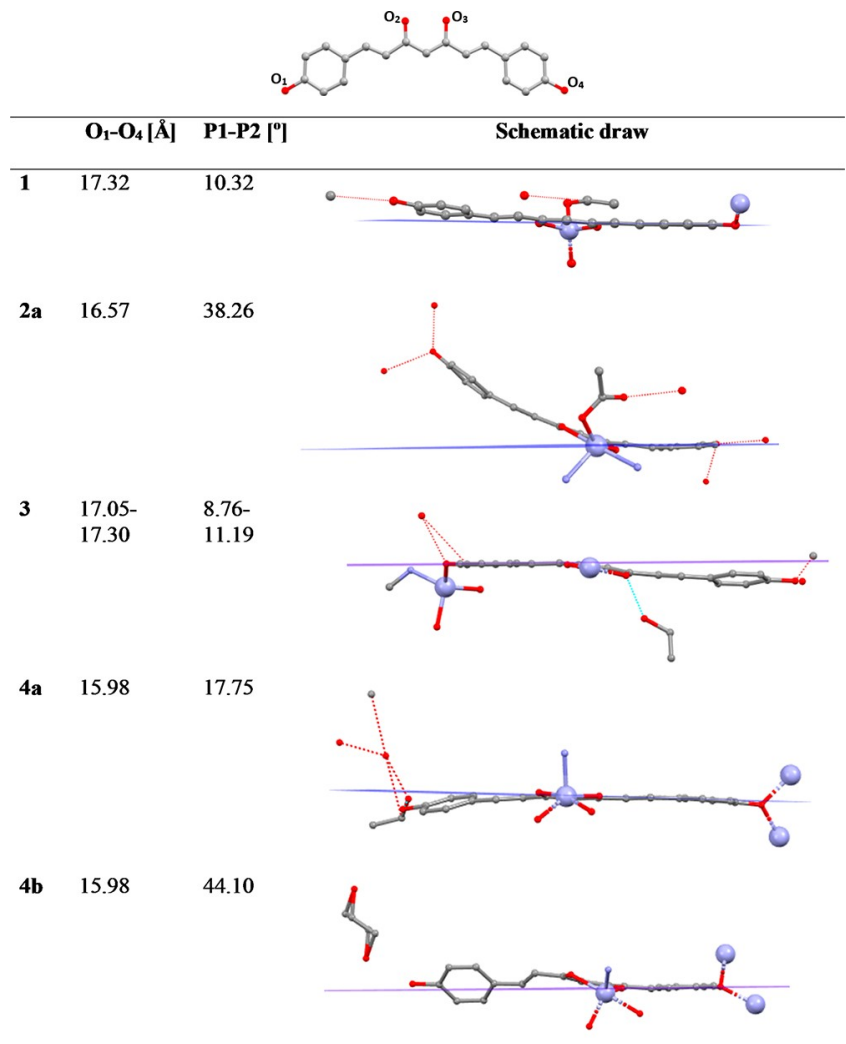

the latest remains interacting with the surrounding and creates hydrogen bonding through both phenol groups that finally restrain the ligand. As a result, the BDMC displayed a curved geometry with a marked P1-P2 angle of $38.26^{\circ}$, which bring together the $\mathrm{O}_{1}-\mathrm{O}_{4}$ atoms to a distance of $16.57 \AA$. On the other hand, compound BDMCZn-3 has an elaborated 3D structure with four independent BDMCmolecules that interact through bridges of EtOH and $\mathrm{H}_{2} \mathrm{O}$ molecules. The result is a low-distortion and almost flat conformation for all the BDMC molecules, with $\mathrm{O}_{1}-\mathrm{O}_{4}$ distances of 17.05-17.30 $\AA$ and P1$\mathrm{P} 2$ angles of $8.76-11.9^{\circ}$. Finally, the BDMCZn-4 series, involving the bpy colinker, exhibits the strongest influence of the adsorbed solvent in the resulting structure. Note that BDMCZn-4a and BDMCZn-4b had the same network stoichiometry, $\left[\mathrm{Zn}_{2}(\mathrm{BDMC})_{2}(\mathrm{bpy})\right]_{n}$, differing in the composition only in the adsorbed solvent molecules $\left(\mathrm{H}_{2} \mathrm{O}\right.$ or EtOH). In BDMCZn-4a, strong hydrogen bonds are established through $\mathrm{H}_{2} \mathrm{O}$ and $\mathrm{EtOH}$ bridges, and here the BDMC adopts a near-planar geometry with a $\mathrm{O}_{1}-\mathrm{O}_{4}$ distance of $17.42 \AA$ and a $\mathrm{P} 1-\mathrm{P} 2$ angle of $17.75^{\circ}$. In a totally different scenario, the adsorbed EtOH molecules in BDMCZn-4b interact weakly with the crystal network. The lack of interaction of the BDMC linkers through solvent bridges results in a highly tensioned molecule with a distorted conformation. As a result, the $\mathrm{O}_{1}-$ $\mathrm{O}_{4}$ distance is $15.98 \AA$ and the $\mathrm{P} 1-\mathrm{P} 2$ angle is $44.10^{\circ}$. Again, the main reason for such a large stretching is the approximation between BDMC molecules to allow short interactions that stabilize the structure with the corresponding higher distortion of the CCMoid skeleton (through the site that remains uncoordinated).

In Figure 8, the structures of the BDMCZn-1/4b systems are compared with the conformation of pristine $\mathrm{BDMC}$ in either solvated crystal either involving $\mathrm{H}_{2} \mathrm{O}$ or unsolvated. Superimposition of the BDMC molecules in the asymmetric unit of each solved structure in this work shows the flexibility of the CCMoid molecule that adopt different conformations. The BDMC disposition in BDMCZn-1, $-2,-3$, and $-4 \mathrm{~b}$ is similar to that found in solvated BDMC (Figure 8a), while BDMCZn-4c has a conformation similar to unsolvated BDMC (Figure 8b).

\section{CONCLUSIONS}

The reaction between $\mathrm{BDMC}$ and $\mathrm{Zn}(\mathrm{OAc})_{2}$ in $\mathrm{EtOH}$ produced the $1 \mathrm{D}$ compound $[\mathrm{Zn}(\mathrm{BDMC})(\mathrm{EtOH})]_{n}$ (BDMCZn-1). BDMC, Zn(II), and the secondary linker bpe formed either a $1 \mathrm{D}$ compound with stoichiometry [Zn$(\mathrm{BDMC})(\mathrm{bpe})(\mathrm{OAc})]_{n} \cdot n \mathrm{H}_{2} \mathrm{O}$ (BDMCZn-2a) or an unresolved phase with an estimated [Zn(BDMC)(bpe $\left.)_{0.5}\right]_{n}$ formula (BDMCZn-2b). On the contrary, the use of either bpp or bpy colinker induced the crystallization of $3 \mathrm{D}$ structures with formula $\left[\mathrm{Zn}(\mathrm{BDMC})(\mathrm{bpp})_{0.5}\right]_{n} \cdot n / 2 \mathrm{EtOH}(\mathrm{BDMCZn}-3)$ and [Zn(BDMC)(bpy) $\left.)_{0.5}\right]_{n} \cdot n$ Solv (Solv $=\mathrm{H}_{2} \mathrm{O}$ and EtOH in BDMCZn-4a, EtOH in $-4 b$ and $2 \mathrm{H}_{2} \mathrm{O}$ in the estimation of $-4 \mathrm{c})$. The BDMC in these structures is coordinated to $\mathrm{Zn}(\mathrm{II})$ by the $\beta$-diketone and one phenolic ring (BDMCZn-1, -2b, -3, $-4 a,-4 b$, and $-4 c$ ) or only through the $\beta$-diketone (BDMCZn$2 \mathrm{a})$. Five of these structures could be structurally elucidated by SCXRD. For unresolved compounds, the main findings obtained by compiling the characterization results achieved by XRD, EA, TGA, ATR-FTIR, and solid-state ${ }^{13} \mathrm{C}$ NMR are (i) BDMCZn-2b incorporates only half of the bpe colinker present in BDMCZn-2a, with [Zn(BDMC)(bpe $\left.)_{0.5}\right]_{n}$ as a feasible formula; (ii) BDMCZn-4a and $-4 \mathrm{~b}$ have similar stoichiometry [Zn(BDMC)(bpy)0.5], but differ in the coordination geometry of $\mathrm{Zn}$ (II) driven by different adsorbed $\mathrm{H}_{2} \mathrm{O}$ / EtOH molecules; and (iii) BDMCZn-4c shows lots of similarities with the corresponding minor phases BDMCZn$4 \mathrm{a}$ and $-4 \mathrm{~b}$, but also shares features with BDMCZn-3. The high mobility present in the arms of the BDMC molecule creates a myriad of possible conformations, giving place to the new family of CPs presented here. The existence of hydrogen bonding stabilizes near-equilibrium conformations, while the absence of these bridges forces the molecule to adopt curved/ shrunk conformations. In all cases, the presence of free phenol groups in the structures opens the possibility of post-synthetic reactions that can modify the properties of these CPs. This factor becomes especially important in a compound like BDMCZn-4a, in which these phenol groups may be easily accessible, resulting in new potential applications for CPs involving renewable linkers, including biomedical uses that would be examined in a future work. Finally, we would like to remark that our results emphasize the use of mild conditions and green solvent in the synthetic methodology; it shows the unanticipated coordination of the BDMC under such conditions and the assistance of $\mathrm{ss}{ }^{13} \mathrm{C}$ NMR toward the analysis of the new CPs. Altogether, this work highlights the potential of BDMC as a polytopic linker and allows a comprehensive understanding of its capabilities for further uses. 


\section{ASSOCIATED CONTENT}

\section{Supporting Information}

The Supporting Information is available free of charge at https://pubs.acs.org/doi/10.1021/acs.cgd.0c00742.

Additional figures of the structures and crystals, powder X-ray diffraction, thermal characterization, ATR-FTIR spectrum, values of the solid-state ${ }^{13} \mathrm{C} \mathrm{NMR}$, and crystallographic details (PDF)

\section{Accession Codes}

CCDC 1991279-1991283 contain the supplementary crystallographic data for this paper. These data can be obtained free of charge via www.ccdc.cam.ac.uk/data_request/cif, or by emailing data_request@ccdc.cam.ac.uk, or by contacting The Cambridge Crystallographic Data Centre, 12 Union Road, Cambridge CB2 1EZ, UK; fax: +44 1223336033.

\section{AUTHOR INFORMATION}

\section{Corresponding Authors}

Concepción Domingo - Instituto de Ciencia de Materiales de Barcelona (ICMAB-CSIC), Bellaterra 08193, Spain; ○ orcid.org/0000-0002-6976-8283; Email: conchi@ icmab.es

Núria Aliaga-Alcalde - Instituto de Ciencia de Materiales de Barcelona (ICMAB-CSIC), Bellaterra 08193, Spain; ICREA, InstitucióCatalana de Recerca i Estudis Avanctss, 08010 Barcelona, Spain; ๑ orcid.org/0000-0003-1080-3862; Email: naliaga@icmab.es,nuria.aliaga@icrea.cat

\section{Authors \\ Laura Rodríguez-Cid - Instituto de Ciencia de Materiales de Barcelona (ICMAB-CSIC), Bellaterra 08193, Spain; - orcid.org/0000-0002-4978-0701 \\ E. Carolina Sañudo - Departament de Químea Inorgàira $i$ Orgaixa and Institut de Nanocienia i Nanotecnologia, Universitat de Barcelona, 08028 Barcelona, Spain; - orcid.org/0000-0001-9647-6406 \\ Ana M. Lopez-Periago - Instituto de Ciencia de Materiales de Barcelona (ICMAB-CSIC), Bellaterra 08193, Spain \\ Arantzazu Gonzalez-Campo - Instituto de Ciencia de Materiales de Barcelona (ICMAB-CSIC), Bellaterra 08193, Spain; orcid.org/0000-0002-1209-8119}

Complete contact information is available at: https://pubs.acs.org/10.1021/acs.cgd.0c00742

\section{Author Contributions}

The manuscript was written through contributions of all authors. All authors have given approval to the final version of the manuscript.

Notes

The authors declare no competing financial interest.

\section{ACKNOWLEDGMENTS}

This work has received funding from the European Research Council (ERC) under the European Union's Horizon 2020 R\&D programme (ERC-724981). We also acknowledge the Spanish Government, Ministerio de Ciencia e Innovación (projects CTQ2017-83632, CTQ2015-68370-P and PGC2018-098630-B-I00 - MAT2016-77852-C2-1-R, and Ramon y Cajal grant RYC-2017-22910) and the Generalitat de Catalunya for the grant 2017SGR1277. C.D., N.A.A., A.L.P., A.G.C., and L.R.C. acknowledge the financial support through the "Severo Ochoa" program for Centres of Excellence in R\&D (SEV-2015-0496) under the FUNMAT-FIP-2016 fellowship. Special thanks to the Alba synchrotron for the possibility of carrying out the measurements of the crystals in the experiments AV-2017042211, AV-2018052864, AV2018072912, and AV-2019023285 at beamline BL13XALOC. This work (L.R.C.) has been done in the framework of the doctoral program "Chemistry" of the Universitat Autonma de Barcelona.

\section{ABBREVIATIONS}

$\mathrm{AI}$, active ingredients; $\mathrm{BDMC}$, bisdemetoxycurcumin; $\mathrm{CP}$, coordination polymers; bpe, 1,2-bis(4-pyridyl)ethylene; bpp, 1,3-bis(4-pyridyl)propane; bpy, 4,4'-bipyridine; CCM, curcumin; CCMoid, curcuminoid; DMC, demethoxycurcumin; EA, elemental analysis; EtOH, ethanol; ATR-FTIR, attenuated total reflectance Fourier transform infrared; MOF, metal organic framework; OAc, acetate; PXRD, powder crystal Xray diffraction; SCXRD, single crystal X-ray diffraction; solidstate ${ }^{13} \mathrm{C}$ NMR, solid state ${ }^{13} \mathrm{C}$ nuclear magnetic resonance; TGA, thermal gravimetric analysis

\section{REFERENCES}

(1) GomollołBel, F. Ten Chemical Innovations That Will Change Our World: IUPAC identifies emerging technologies in Chemistry with potential to make our planet more sustainable. Chem. Int. 2019, 41, 12-17.

(2) El-Sayed,E. S.M.; Yuan, D. Waste to MOFs: sustainablelinker, metal, and solvent sources for value-added MOF synthesis and applications. Green Chem. 2020, 22, 4082-4104.

(3) Abrahams, B. F.; Moylan, M.; Orchard, S. D.; Robson, R. Zinc Saccharate: A Robust, 3D coordination network with two types of isolated, parallel channels, one hydrophilic and the other hydrophobic. Angew. Chem., Int. Ed. 2003, 42, 1848-1851.

(4) Navarro-Sánhez, J.; Argente-García, A. I.; Moliner-Martínez; Roca-Sanjuan D.; Antypov, D.; Campíns-FalcóP.; Rosseinsky, M. J.; Martí-Gastaldo, C. Peptide metal-organic frameworks for enantioselective separation of chiral drugs. J. Am. Chem. Soc. 2017, 139, 42944297.

(5) Lillo, V.; GalanMascaros J. R. Transition metal complexes with oligopeptides: single crystals and crystal structures. Dalt. Trans. 2014 43, 9821-9833.

(6) Marabello, D.; Antoniotti, P.; Benzi, P.; Canepa, C.; Diana, E.; Operti, L.; Mortati, L.; Sassi, M. P. Non-linear optical properties of $\beta$ D-fructopyranose calcium chloride MOFs: an experimental and theoretical approach. J. Mater. Sci. 2015, 50, 4330-4341.

(7) Xie, Y.; Yu, Z.; Huang, X.; Wang, Z.; Niu, L.; Teng, M.; Li, J. Rational design of MOFs constructed from modified aromatic amino acids. Chem. - Eur. J. 2007, 13, 9399-9405.

(8) Pratibha; Verma, S. Imine component based modified adenine nucleobase-metal frameworks. Cryst. Growth Des. 2015, 15, 510-516.

(9) Wilcox, O. T.; Fateeva, A.; Katsoulidis, A. P.; Smith, M. W.; Stone, C. A.; Rosseinsky, M. J. Acid loaded porphyrin-based metalorganic framework for ammonia uptake. Chem. Commun. 2015, 51, 14989-14991.

(10) Smaldone, R. A.; Forgan, R. S.; Furukawa, H.; Gassensmith, J. J.; Slawin, A. M. Z.; Yaghi, O. M.; Stoddart, J. F. Metal-organic frameworks from edible natural products. Angew. Chem., Int. Ed. 2010, 49, 8630-8634.

(11) Keskin, S.; Kizılel, S. Biomedical applications of metal organic frameworks. Ind. Eng. Chem. Res. 2011, 50, 1799-1812.

(12) Cai, W.; Chu, C.; Liu, G.; Wang, Y.Metal-organic frameworkbased nanomedicine platforms for drug delivery and molecular imaging. Small 2015, 11, 4806-4822. 
(13) Reddy, S.; Vasavi, A.; Suresh, J.; Yadav, H.; Singh, A. A Review on Curcuma longa - ProQuest. Res. J. Pharm. Technol. Raipur. 2012, 5.2, $158-165$.

(14) Pabon, H. J. J. A synthesis of curcumin and related compounds. Recl. des Trav. Chim. des Pays-Bas. 1964, 83 (4), 379-386.

(15) Nurfina, A. N.; Reksohadiprodjo, M. S.; Timmerman, H.; Jenie, U. A.; Sugiyanto, D.; Van der Goot, H. Synthesis of some symmetrical curcumin derivatives and their antiinflammatory activity. Eur. J. Med. Chem. 1997, 32, 321-328.

(16) Pedersen, U.; Rasmussen, P. B.; Lawesson, S. O. Synthesis of naturally occurring curcuminoids and related compounds. Liebigs Annalen der Chemie. 1985, 1985, 1557-1569.

(17) Kunnumakkara, A. B.; Guha, S.; Krishnan, S.; Diagaradjane, P.; Gelovani, J.; Aggarwal, B. B. Curcumin potentiates antitumor activity of gemcitabine in an orthotopic model of pancreatic cancer through suppression of proliferation, angiogenesis, and inhibition of nuclear factor-KB-regulated gene products. Cancer Res. 2007, 67, 3853-3861.

(18) Dandawate, P. R.; Vyas, A.; Ahmad, A.; Banerjee, S.; Deshpande, J.; Swamy, K. V.; Sarkar, F. H. Inclusion complex of novel curcumin analogue CDF and $\beta$-cyclodextrin (1:2) and its enhanced in vivo anticancer activity against pancreatic cancer. Pharm. Res. 2012, 29, 1775-1786.

(19) Maheshwari, R. K.; Singh, A. K.; Gaddipati, J.; Srimal, R. C. Multiple biological activities of curcumin: a short review. Life Sci. 2006, 78, 2081-2087.

(20) Claramunt, R. M.; Lavandera, J. L.; Alkorta, I.; Elguero, J. Curcumin and curcuminoids: Chemistry, structural studies and biological properties. An. Real Acad. Nac. Farm. 2015, 81, 278-310.

(21) Zhang, Y.; Khan, A. R.; Fu, M.; Zhai, Y.; Yu, A.; Zhai, G. The progresses in curcuminoids-based metal complexes: especially in cancer therapy. Future Med. Chem. 2019, 11, 1035-1056.

(22) Pettinari, R.; Marchetti, F.; Condello, F.; Pettinari, C.; Lupidi, G.; Scopelliti, R.; Mukhopadhyay, S.; Riedel, T.; Dyson, P. J. Ruthenium(II)-arene RAPTA type complexes containing curcumin and bisdemethoxycurcumin display potent and selective anticancer activity. Organometallics 2014, 33, 3709-3715.

(23) Pettinari, R.; Marchetti, F.; Pettinari, C.; Condello, F.; Petrini, A.; Scopelliti, R.; Riedel, T.; Dyson, P. J. Organometallic rhodium(III) and iridium(III) cyclopentadienyl complexes with curcumin and bisdemethoxycurcumin co-ligands. Dalton T. 2015, 44, 20523-20531.

(24) Krishnankutty, K.; Venugopalan, P. Metal chelates of curcuminoids. Synth. React. Inorg. Met.-Org. Chem. 1998, 28, 13131325.

(25) Li, Y.; Gu, Z.; Zhang, C.; Li, S.; Zhang, L.; Zhou, G.; Wang, S.; Zhang, J. Synthesis, characterization and ROS-mediated antitumor effects of palladium (II) complexes of curcuminoids. Eur. J. Med. Chem. 2018, 144, 662-671.

(26) Su, H.; Sun, F.; Jia, J.; He, H.; Wang, A.; Zhu, G. A highly porous medical metal-organic framework constructed from bioactive curcumin. Chem. Commun. 2015, 51, 5774-5777.

(27) PortolésGil, N.; Lanza, A.; Aliaga-Alcalde, N.; Ayllón J. A.; Gemmi, M.; Mugnaioli, E.; Lópz-Periago, A. M.; Domingo, C. Crystalline Curcumin bioMOF Obtained by Precipitation in Supercritical CO2 and Structural Determination by Electron Diffraction Tomography. ACS Sustainable Chem. Eng. 2018, 6, 12309-12319.

(28) Díaz-Torres, R.; Menelaou, M.; Gonzalez-Campo, A.; Teat, S. J.; Sañudo, E. C.; Soler, M.; Aliaga-Alcalde, N. Comparative Magnetic Studies in the Solid State and Solution of Two Isostructural 1D Coordination Polymers Containing CoII/NiII-Curcuminoid Moieties. Magnetochemistry. 2016, 2, 29.

(29) Manna, B.; Desai, A. V.; Ghosh, S. K. Neutral N-donor ligand based flexible metal-organic frameworks. Dalton Trans. 2016, 45, 4060-4072.

(30) Haldar, R.; Maji, T. K. Metal-organic frameworks (MOFs) based on mixed linker systems: structural diversities towards functional materials. CrystEngComm 2013, 15, 9276-9295.

(31) Duer, M. J. Solid state NMR spectroscopy: principles and applications, Dier, M. J., Ed.; John Wiley \& Sons, 2008; pp 483-485.
(32) Sheldrick, G. M. Crystal structure refinement with SHELXL. Acta Crystallogr., Sect. C: Struct. Chem. 2015, 71, 3-8.

(33) Juanhuix, J.; Gil-Ortiz, F.; Cuní, G.; Colldelram, C.; Nicolás, J.; LidonJ.; Boter, E.; Ruget, C.; Ferrer, S.; Benach, J. Developments in optics and performance at BL13-XALOC, the macromolecular crystallography beamline at the Alba Synchrotron. J. Synchrotron Radiat. 2014, 21, 679-689.

(34) Kabsch, W. Xds. Acta Crystallogr., Sect. D: Biol. Crystallogr. 2010, 66, 125-132.

(35) Dong, L.; Chu, W.; Zhu, Q.; Huang, R. Three Novel Homochiral Helical Metal-Organic Frameworks Based on Amino Acid Ligand: Syntheses, Crystal Structures, and Properties. Cryst. Growth Des. 2011, 11, 93-99.

(36) Singh, W. M.; Baruah, J. B. Nickel, copper and zinc complexes of (2-methoxycarbonylmethylimino-5-methyl-thiazol-3-yl)-acetic acid. Polyhedron 2008, 27, 2968-2972.

(37) Aliaga-Alcalde, N.; Rodríguez, L.; Ferbinteanu, M.; Höfer, P.; Weyhermuller, T. Crystal structure, fluorescence, and nanostructuration studies of the first $\mathrm{ZnII}$ anthracene-based curcuminoid. Inorg. Chem. 2012, 51, 864-873.

(38) Matlinska, M. A.; Wasylishen, R. E.; Bernard, G. M.; Terskikh, V. V.; Brinkmann, A.; Michaelis, V. K. Capturing elusive polymorphs of curcumin: A structural characterization and computational study. Cryst. Growth Des. 2018, 18, 5556-5563.

(39) Pöppler, A. C.; Lubtow, M. M.; Schlauersbach, J.; Wiest, J.; Meinel, L.; Luxenhofer, R. Loading-Dependent Structural Model of Polymeric Micelles Encapsulating Curcumin by Solid-State NMR Spectroscopy. Angew. Chem., Int. Ed. 2019, 58, 18540-18546.

(40) Kong, X.; Brinkmann, A.; Terskikh, V.; Wasylishen, R. E.; Bernard, G. M.; Duan, Z.; Wu, G. Proton probability distribution in the $\mathrm{O} \cdots \mathrm{H} \cdots \mathrm{O}$ low-barrier hydrogen bond: a combined solid-state NMR and quantum chemical computational study of dibenzoylmethane and curcumin. J. Phys. Chem. B 2016, 120 (45), 1169211704.

(41) Volkringer, C.; Popov, D.; Loiseau, T.; Guillou, N.; Ferey, G.; Haouas, M.; Taulelle, F.; Mellot-Draznieks, C.; Burghammer, M.; Riekel, C. A microdiffraction set-up for nanoporous metal-organicframework-type solids. Nat. Mater. 2007, 6, 760-764.

(42) Stegbauer, L.; Schwinghammer, K.; Lotsch, B. V. A hydrazonebased covalent organic framework for photocatalytic hydrogen production. Chem. Sci. 2014, 5, 2789-2793.

(43) Kolev, T. M.; Velcheva, E. A.; Stamboliyska, B. A.; Spiteller, M. DFT and experimental studies of the structure and vibrational spectra of curcumin. Int. J. Quantum Chem. 2005, 102, 1069-1079.

(44) Kaljurand, I.; Lilleorg, R.; Murumaa, A.; Mishima, M.; Burk, P.; Koppel, I.; Koppel, I. A.; Leito, I. The Basicity of Substituted N,NDimethylanilines in Solution and in the Gas Phase. J. Phys. Org. Chem 2013, 26 (2), 171-181.

(45) Yuan, L.; Lorenz, H. Solvate formation of bis (demethoxy) curcumin: Screening and characterization. Crystals 2018, 8, 407.

(46) Yuan, L.; Horosanskaia, E.; Engelhardt, F.; Edelmann, F. T.; Couvrat, N.; Sanselme, M.; Cartigny, Y.; Coquerel, G.; SeidelMorgenstern, A.; Lorenz, H. Solvate Formation of Bis (demethoxy) curcumin: Crystal Structure Analyses and Stability Investigations. Cryst. Growth Des. 2019, 19 (2), 854-867.

(47) Karlsen, J.; Mostad, A.; Tønnesen, H. H.; et al. Structural studies of curcuminoids. VI. Crystal structure of 1,7-bis(4hydroxyphenyl)-1,6-heptadiene-3,5-dione hydrate. Acta Chem. Scand. 1988, 42, 23-27. 